\title{
ESTUDO DE TRATAMENTOS ALTERNATIVOS PARA A REDUÇÃO DA ACIDEZ NO SEBO BOVINO
}

\author{
L. A. FERREIRA ${ }^{1}$, N. C. PEREIRA ${ }^{1}$, S. M. OLIVEIRA ${ }^{1}$ e P. O. R. BERTO ${ }^{1}$ \\ ${ }^{1}$ Universidade Estadual de Maringá, Departamento de Engenharia Química \\ E-mail para contato: lidia_a.f@hotmail.com
}

\begin{abstract}
RESUMO - O objetivo deste trabalho foi desenvolver formas alternativas para reduzir a acidez do sebo bovino para a produção de biodiesel. Foram realizados testes com dois reagentes: éter petróleo e bicarbonato de sódio, em diferentes concentrações. Verificouse que o solvente éter petróleo tem grande potencial para diluir o sebo, com capacidade até para diminuir o ponto de fusão do mesmo. Esse fato facilita a remoção de sujidades responsáveis pelo aumento da acidez. O tratamento com bicarbonato de sódio foi realizado em batelada variando temperatura, composição, rotação e tempo. Neste caso foi observado que uma rotação baixa, com composição de $5 \%$ de bicarbonato de sódio e tempo de reação de 1 hora, mostrou ser mais eficiente para a redução da acidez. Esta técnica apresentou melhor eficácia. Podemos concluir que os reagentes avaliados apresentaram resultados positivos sob a redução da acidez do sebo bovino, porém o bicarbonato de sódio teve contribuição mais expressiva.
\end{abstract}

\section{INTRODUÇÃO}

As gorduras animais podem ser classificadas como matéria prima renovável com grande potencial para a produção de biodiesel, segundo Bellaver (2005) os volumes de sebo bovino, graxa suína e óleo de aves gerados no abate são de 1.560.000, 355.000 e 218.000 ton/ano, respectivamente.

O sebo bovino já representa $19,60 \%$ de todo biodiesel produzido no Brasil, sendo que na região sudoeste esta porcentagem sobe para 48,23\%, ultrapassando a produção utilizando óleo de soja (ANP, 2013). Porém apesar da grande potencialidade do uso do sebo bovino como matéria prima, existem poucos trabalhos na literatura sobre este tema devido a algumas dificuldades no seu processamento. Um dos obstáculos que se pode mencionar são as impurezas, elas interferem diretamente no processo de produção de biodiesel, pois diminuem o rendimento do processo, aumentam os subprodutos secundários e dificultam os processos de separação e purificação do biodiesel e do glicerol, em especial quando se utiliza catalisadores convencionais: $\mathrm{NaOH}, \mathrm{KOH}$ e metilato de sódio.

Diante disso há a clara necessidade de investimento em novos estudos a respeito da caracterização e tratamento do sebo bovino. Neste trabalho é estudada uma forma viável de tratamento do sebo bovino para que este apresente uma menor quantidade de impurezas e um menor índice de acidez, visando criar as melhores condições para obtenção do biodiesel. 


\section{OBJETIVO}

O objetivo principal é a busca de um tratamento viável e eficaz para sebo bovino com o intuito de criar melhores condições para produção de biodiesel. Uma vez que esta matéria prima isenta de tratamento possui características desfavoráveis para a obtenção de biodiesel.

\section{MATERIAIS E MÉTODOS}

\subsection{Caracterização da matéria prima}

Cromatografia a gás: A cromatografia foi realizada em um cromatógrafo marca Thermo Scientific, modelo Trage GC Ultra. Com uma coluna da marca SGE Analytical Science, modelo BPX 70.

Umidade: O teor de umidade foi determinado pelo titulador Karl Fischer onde reagente Karl Fisher é constituído por uma mistura de iodo, dióxido de enxofre e piridina em metanol, com este reagente podem ser determinadas pequenas quantidades de água. Ocorre uma reação onde o iodo é reduzido pelo dióxido de enxofre, na presença da água. Esta análise foi feita mensalmente.

Índice de saponificação: Este índice mostra a quantidade de óleo que foi usado para saponificar a análise é feita pelo seguinte procedimento: em um erlenmeyer de $250 \mathrm{~mL}$, coloca-se uma alíquota de $\pm 2 \mathrm{~g}$ de óleo. Com auxilio de uma bureta, adicionar $25 \mathrm{~mL}$ de solução alcoólica de hidróxido de potássio 0,5M. Adaptar o erlenmeyer em condensador de refluxo. Ferver durante 30 minutos em banho-maria, agitando de vez em quando. Resfriar um pouco. Adicionar 2 gotas do indicador fenolftaleína. Titular a quente o excesso de potássio com acido clorídrico $0,5 \mathrm{M}$ até que a coloração rósea desapareça. Efetuar paralelamente uma titulação em branco nas mesmas condições, mas sem a presença do óleo. A diferença entre os números de $\mathrm{mL}$ de acido clorídrico gastos nas duas titulações é equivalente a quantidade de hidróxido de potássio gasto na saponificação.

Índice de acidez: A determinação da acidez é um dos dados mais importantes deste trabalho tanto na avaliação da eficiência do tratamento como na avaliação do estado de conservação do óleo. O índice de acidez é como o número de mg de hidróxido de potássio necessário para neutralizar um grama da amostra. O método é aplicável a óleos brutos e refinados, vegetais e animais, e gorduras animais. Os métodos que avaliam a acidez titulável resumem-se em titular, com soluções de álcali-padrão, a acidez do produto ou soluções aquosas/alcoólicas do produto, assim como os ácidos graxos obtidos dos lipídios. O índice de acidez foi determinado de acordo com o método AOCS Ca 5-40.

Densidade: O objetivo da análise é determinar a densidade do óleo proveniente da matéria-prima escolhida para a produção do biocombustível, que no caso é o sebo bovino, utilizando um densímetro. A densidade foi determinda em um densímetro da marca Anton Paar, modelo DMA 5000. 


\subsection{Tratamentos}

Tratamento via adição de bicarbonato de sódio: O bicarbonato de sódio assim como hidróxido de sódio, reage com ácido graxo livre para formar um sal solúvel (carboxilato). A reação é dada a seguir:

$$
\mathrm{CH}_{3} \mathrm{COOH}+\mathrm{NaHCO}_{3} \rightarrow \mathrm{CH}_{3} \mathrm{COONa}+\mathrm{CO}_{2}+\mathrm{H}_{2} \mathrm{O}
$$

Procedimento: para encontrar a proporção de sebo e bicarbonato que proporciona um melhor rendimento, foi feita uma análise da influencia da temperatura, tempo de agitação e quantidade de reagentes. Com o auxílio de um banho e um agitador é misturada uma quantidade fixa de sebo e variado a concentração de bicarbonato de sódio durante certo tempo, em seguida é variado e tempo com uma concentração de bicarbonato de sódio fixa, analisando sempre a influência da temperatura do banho e agitação da mistura dos reagentes.

Tratamento via éter petróleo: O mesmo estudo que foi feito para o bicarbonato de sódio foi feito para o éter petróleo, ou seja, variou-se as mesma variáveis, porém para analisarmos a acidez do produto pós reação foi necessário rotaevaporar o éter petróleo em excesso por meio de um rotaevaporador na temperatura de $70^{\circ} \mathrm{C}$ por aproximadamente 1 hora.

\section{RESULTADOS}

\subsection{Caracterização da matéria prima}

O acompanhamento da matéria prima foi feito mensalmente por meio da caracterização, onde foi possível notar que o maior valor de teor de ácidos graxos livres obtido foi de aproximadamente $10 \%$, que esta muito acima do limite especificado por Bellaver e Zanotto (2004) de até 3\% de ácidos graxos livres. Os dados constam na tabela 02.

Tabela 02 - Caracterização mensal da matéria prima.

\begin{tabular}{c|c|c|c|c}
\hline \multicolumn{5}{|c|}{ Caracterização Sebo bovino } \\
\hline & Umidade (\%) & $\begin{array}{c}\text { Índice de Acidez } \\
(\mathrm{mgNaOH} / \mathrm{g} \text { óleo) }\end{array}$ & $\begin{array}{c}\text { Índice de } \\
\text { Saponificação }(\mathrm{mg} \\
\text { KOH/g óleo) }\end{array}$ & Densidade (g/mL) \\
\hline 1 & 0,219 & $21,88 \pm 0,03$ & $213,71 \pm 2,71$ & 0,895666 \\
\hline 2 & 0,202 & $20,84 \pm 0,38$ & $196,61 \pm 7,46$ & 0,893456 \\
\hline 3 & 0,198 & $20,71 \pm 0,45$ & $190,57 \pm 3,96$ & 0,905478 \\
\hline 4 & 0,197 & $18,17 \pm 0,95$ & $196,41 \pm 0,30$ & 0,909874 \\
\hline 5 & 0,200 & $17,89 \pm 0,15$ & $197,95 \pm 2,38$ & 0,907901 \\
\hline
\end{tabular}

A umidade do sebo varia com tempo, mas especificamente com a mudança climática. Em tempos chuvosos, o sebo tem maior umidade e em tempos secos, menor. A acidez está intimamente ligada a este fato, pois o aumento da umidade faz com que a matéria prima 


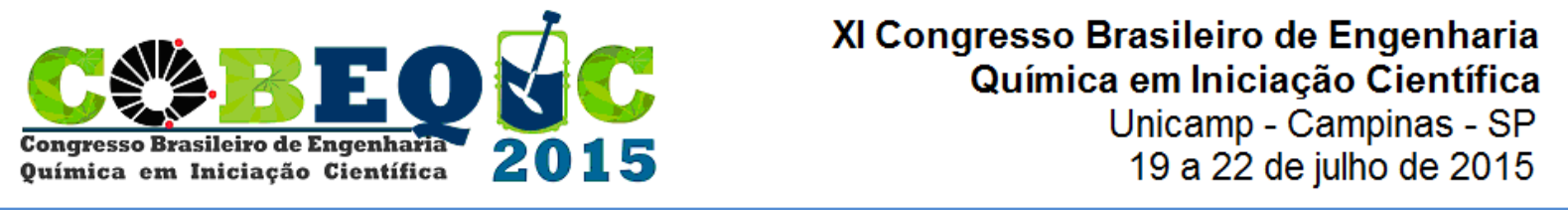

adquira uma característica mais ácida, o que seria indesejável para fins de produção de biodiesel.

\subsection{Tratamento via Éter Petróleo}

Para o tratamento com éter petróleo foi fixada a massa de sebo bovino em $100 \mathrm{~g}$ e variada a massa de éter. Após a reação o éter foi destilado e foram feitas as análises do índice de acidez.

De posse dos resultados preliminares, foi possível determinar o intervalo onde a variação do índice de acidez foi mais significativo. Logo o tratamento do sebo com éter petróleo foi refeito, só que agora com um numero maior de pontos, onde a análise foi feita até $35 \%$ de éter petróleo em $100 \mathrm{~g}$ de Sebo bovino. Os dados estão dispostos na figura 02.

Figura 02 - Índice de acidez com relação à quantidade de éter petróleo.

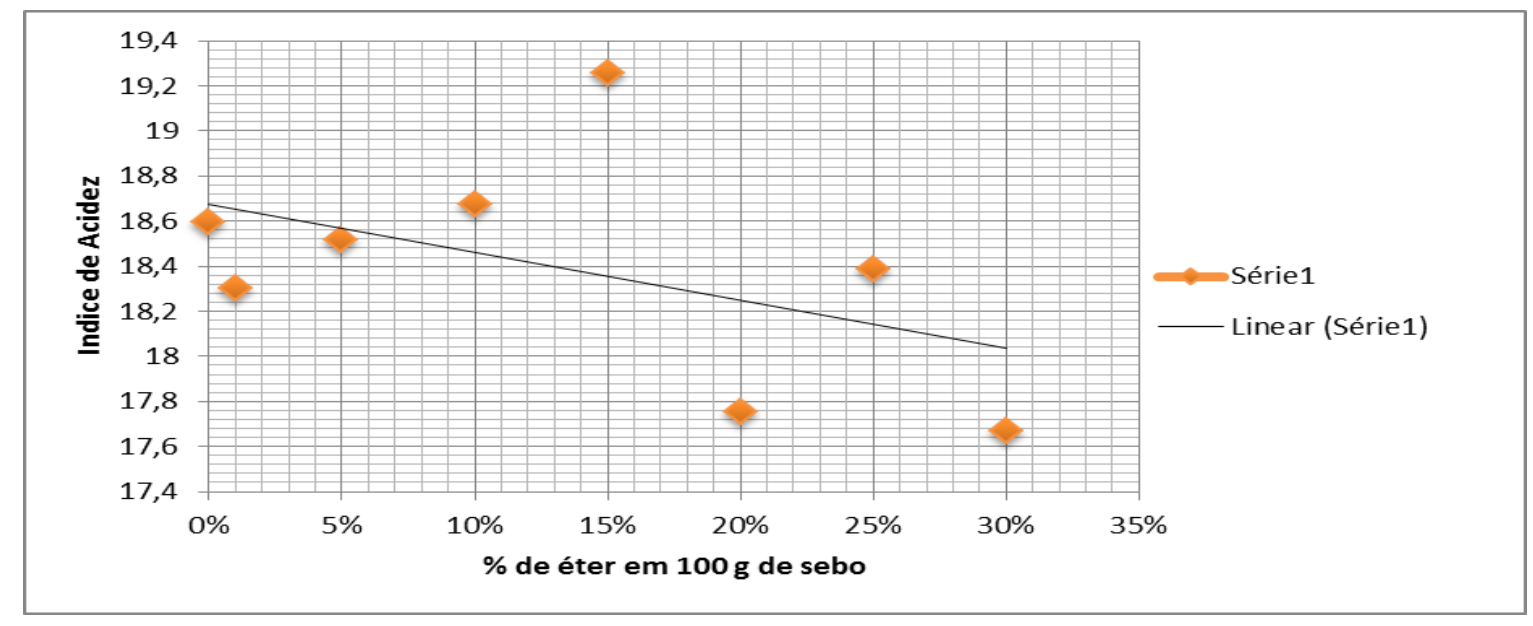

\subsection{Tratamento via bicarbonato de sódio}

Através dos experimentos preliminares foi possível desenvolver um planejamento fatorial. Utilizou se de um Delineamento Composto Central Rotacional (DCCR) com 3 variáveis (\% de bicarbonato, tempo e temperatura) com 4 repetições no ponto central. Tomando como base para o ponto central os dados anteriores. O erro experimental foi obtido por meio da média e desvio padrão dos pontos centrais. A Tabela 3 mostra a descrição do planejamento.

Tabela 03 - Valores utilizados no DCCR.

\begin{tabular}{cccccc}
\hline Niveis & -1.68 & -1 & 0 & 1 & 1.68 \\
\hline \% Bicarbonato & 1 & 2.62 & 5 & 7.98 & 10 \\
\hline Temp. $^{\circ} \mathrm{C}$ & 50 & 54.05 & 60 & 71.90 & 80 \\
\hline Tempo $(\mathrm{min})$ & 30 & 42.14 & 60 & 77.86 & 90 \\
\hline
\end{tabular}


Por meio do programa Statistica 8.0 foi possível plotar a superfície de resposta, onde o ajuste do modelo foi avaliado pelo coeficiente de determinação $R^{2}$, cujo valor foi 0,4772 , indicando que $47,72 \%$ da variabilidade das respostas podem ser explicados pelo modelo.

Figura 03 - Gráficos da desirabilitycontours do modelo.
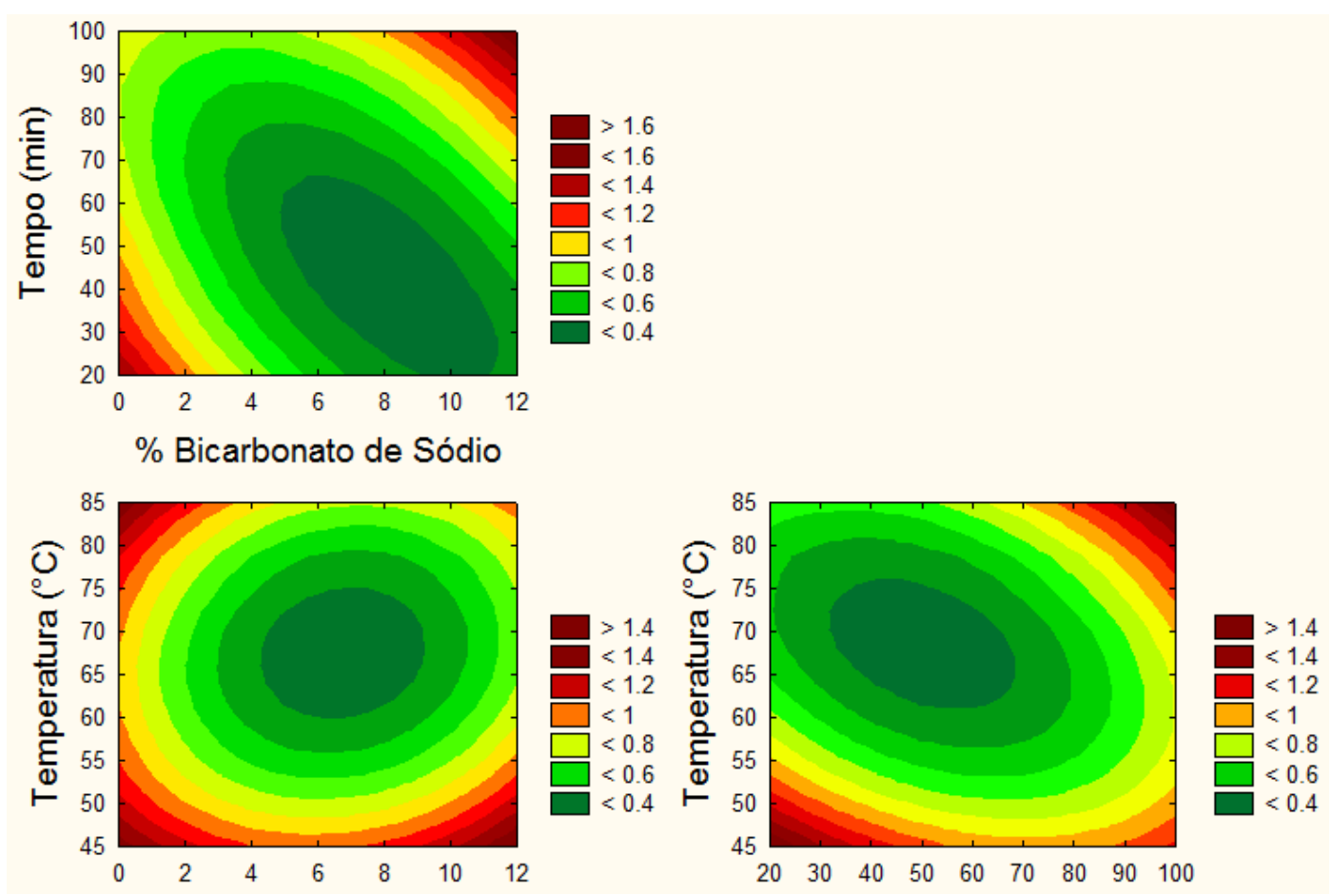

Onde a área vermelha escura no gráfico indica um índice de acidez bem elevado $>24$ enquanto a área verde escura representa um índice baixo $<16$. Com programa estatístico também foi possível calcular a pontos críticos das curvas, ou seja, o valor em temos o menor índice de acidez. Logo temos que para um valor de acidez baixo é preciso que a massa de bicarbonato seja $10,2 \%$ o tempo seja 21,2 min e a temperatura seja $74,9^{\circ} \mathrm{C}$.

\section{CONCLUSÃO}

Por meio da caracterização do sebo foi possível observar que o índice de acidez é a análise que mostrou maior flutuação em relação às outras análises. Podemos então relacionar esta flutuação com a umidade da matéria, que acompanha esta flutuação.

Observou-se então que o fator que leva ao aumento do índice de acidez é a umidade juntamente com o tempo de armazenamento da matéria-prima.

Com relação ao tratamento com éter petróleo observou-se que não houve diminuição significante da acidez com os percentuais de éter petróleo analisados, pois é importante também conhecer a viabilidade do processo com relação ao custo. Logo, quantidades de éter petróleo acima de $50 \%$ de $100 \mathrm{~g}$ de sebo podem ser inviáveis economicamente além de que acima deste valor a acidez do sebo bovino mantém se praticamente constante. Por outro lado a adição de éter petróleo ao sebo diminui a densidade do sebo, de modo que este passa a ter menor ponto de fusão ampliando assim a capacidade de produção de diversos produtos que 
sirvam de matérias primas para a produção de biodiesel. Além de diminuir a temperatura de fusão da matéria, diminuindo conseqüentemente gastos energéticos.

Para a análise do tratamento via bicarbonato de sódio, depois de vários ensaios e análise, verificou-se que o tempo necessário não deve ser 21,2 min e que a agitação deve ser branda, desta forma se produz pouco sabão. Observou-se que uma alta agitação facilitava a formação de sabão devido a presença de uma grande massa que se formava ao final de reação. A variável de maior significância é a massa de bicarbonato adicionada. Observou se que com uma pequena quantidade $(10 \%)$ de bicarbonato de sódio, foi possível diminuir significativamente a acidez do sebo bovino. Vale ressaltar que a adição de bicarbonato acima do necessário apresenta dificuldades na mistura dos reagentes, formando também grande concentração de sabão. Este sabão formado pode ser facilmente retirado por decantação, ficando apenas produto desejado, o sebo bovino neutro.

\section{REFERENCIAS}

GHAZAVI, M. A.; FALLAHIPANAH, M. e JESHVAGHANI, H. S. A feasibility study on beef tallow conversion to some esters for biodiesel production, 2012.

RAMOS, J. C.; HEIDEMANN, T. e RODRIGUEZ, M. A. A. Caracterização e pré-tratamento da matéria prima para a obtenção de biodiesel a partir de óleo de cozinha usado. UTFPR, Campo Mourão.

CHRISTOFF, P. Produção de biodiesel a partir do óleo residual de fritura comercial. IEP, Curitiba, 2006.

NETO, P. R. C. e FREITAS, R. J. S. Purificação do óleo de fritura. B.CEPPA, Curitiba, v. 14, n. 2, p. 163-170, 1996.

MAGALHÃES, F. C. Blenda sebo/soja para produção de biodiesel: Proposta de um processo batelada homogêneo como alternativa para agricultura familiar, 2010, Dissertação (Mestrado em Química Tecnologia e Ambiental), Universidade Federal do Rio Grande, Rio Grande, 77p.

ABREU, P. G.; HIGARASHI, M. M. e JUNIOR, A. C. Transesterificação com catálise ácida de resíduos de gordura de frango para produção de biodiesel, Embrapa Suínos e Aves.

ENCARNAÇÃO, A. P. G. Geração de biodiesel pelos processos de transesterificação e hidroesterificação, uma avaliação econômica, Dissertação de mestrado, UFRJ, Rio de janeiro, 2008.

RAMALHO, H. F.; SUAREZ, P. A. Z. A Química dos Óleos e Gorduras e seus Processos de Extração e Refino. Artigo, Rev. Virtual Quim., 2013. 